\title{
EFICÁCIA DO HERBICIDA DIQUAT NA DESSECAÇÃO EM PRÉ-COLHEITA DA CULTURA DO FEIJÃO
}

\author{
Jeferson Zagonel ${ }^{1}$, Wilson S. Venancio ${ }^{2}$ e Antonio M. de Sousa Neto ${ }^{3}$
}

\author{
'Eng..$^{\circ}$ Agr. ${ }^{\circ}$, Dr., Professor. Universidade Estadual de Ponta Grossa. Praça Santos Andrade, 1. Ponta Grossa, PR 84010-919 \\ jefersonzagonel@uol.com.br \\ ${ }^{2}$ Eng. ${ }^{\circ}$ Agr. ${ }^{\circ}$ MSc, Professor. Universidade Estadual de Ponta Grossa. \\ ${ }^{3}$ Eng. ${ }^{\circ}$ Agr. ${ }^{\circ}$, Syngenta Proteção de Cultivos Ltda.
}

\section{RESUMO}

O momento ideal para realizar a colheita do feijão é após a maturação fisiológica, quando o vigor, a germinação e o peso da matéria seca são elevados. A colheita mecânica, nesta ocasião, é difícil em razão da alta umidade dos grãos e do elevado número de folhas verdes, além de implicar em injúrias mecânicas nas sementes. $\mathrm{O}$ uso de dessecantes pode minimizar este problema, por promover uniformidade das plantas na colheita e redução da umidade dos grãos. Visando avaliar a eficácia agronômica do herbicida diquat na dessecação em pré-colheita da cultura do feijão, foi instalado um experimento em Ponta Grossa, PR, no ano agrícola 1999/00, utilizando-se a cultivar FT Nobre. O delineamento experimental foi de blocos ao acaso com seis tratamentos e quatro repetições. Os tratamentos, aplicados 14 dias antes da colheita, foram: diquat nas doses de 200, 300,400 e $500 \mathrm{~g} / \mathrm{ha}$, amônio-glufosinato na dose de $400 \mathrm{~g} / \mathrm{ha}$ e testemunha absoluta. O diquat nas doses igual ou superiores a $300 \mathrm{~g} / \mathrm{ha}$ e o amônio-glufosinato foram eficientes no controle/desfolha de Bidens pilosa, Eleusine indica e Digitaria horizontalis. Todos os tratamentos foram eficazes na desfolha das plantas de feijão a partir de quatro dias após a aplicação, indicando a possibilidade da antecipação da colheita. Entre os dessecantes utilizados e a testemunha não foram observadas diferenças na produtividade, na germinação e no vigor das sementes.

Palavras-chave: Phaseolus vulgaris, dessecantes.

\section{ABSTRACT \\ Diquat defoliation efficiency on pre harvest bean crop}

The best time to harvest the bean crop is after the occurrence of physiological maturation, when the seeds vigour, the gemination and the weight of dry matter are high. To carry out mechanical harvesting at this moment is difficult because a high number of leaves is still green. Besides, the mechanical injuries may be inflicted on the seeds. The use of defoliation can minimize this occurrence, promoting uniformity of plants maturity at harvest with grains maintaining low moisture. In order to evaluate the agronomic efficiency on defoliation of diquat at pre harvest of the bean crop, an experiment was carried out in Ponta Grossa (PR), during 1999/00, using the cultivar FT Nobre. The experimental design was a randomised block with six treatments and four replications. The following treatments were tested with applications 14 days before harvesting: diquat $(200,300,400$ and $500 \mathrm{~g} / \mathrm{ha})$, ammonium-glufosinate (400 g/ha) and control. Diquat at doses equal to or higher than $300 \mathrm{~g} /$ ha and ammonium-glufosinate showed efficiency in the control (or defoliation) of Bidens pilosa, Eleusine indica and Digitaria horizontalis. All treatments showed efficiency for plant defoliation after four days of application, indicating the possibility of anticipation of harvest. Differences in seed germination, vigour, health and even on the yield among the treatments, including the control were not observed.

Key-words: Phaseolus vulgaris, dessicants. 
Jeferson Zagonel et al.

\section{INTRODUÇÃO}

O aumento do preço do feijão ocorrido nos últimos anos, tem levado os agricultores a empregar uma maior quantidade de insumos nas lavouras, devendo estes serem utilizados adequadamente para maximizar sua eficiência. O manejo das plantas daninhas, com o uso de herbicidas, se destaca como um dos fatores mais importantes para garantir altas produtividades, o objetivo principal dos agricultores.

O controle das plantas daninhas consiste na adoção de práticas culturais que proporcionem redução da infestação, sem, entretanto, preocupar-se em manter a lavoura completemente no limpo (Lorenzi, 1994). O período em que as plantas daninhas causam maiores danos na produtividade foi denominado por Pitelli \& Durigan (1984) como período crítico de prevenção da interferência. No feijão, este periodo ocorre entre 10 e 30 dias após a emergência (Almeida et al., 1989; Gelmini \& Roston, 1980; Zagonel et al., 1999). Após este período, as plantas daninhas não afetam diretamente a produtividade, porém, a presença destas pode prejudicar a operação de colheita, tanto a manual como a mecânica (Rodrigues et al., 1989).

O momento ideal para se efetuar a colheita do feijão é após a maturação fisiológica, quando o vigor, a germinação e o peso da matéria seca são elevados. No entanto, quando colhida nesta ocasião, a planta ainda se encontra com uma quantidade relativamente alta de folhas e ramos verdes e úmidos que dificultam o uso de colhedoras, além de ocorrer maior injúria mecânica, devido ao elevado teor de água nas sementes (Portela \& Cobucci, 1999). Por outro lado, quando a colheita é realizada após a maturação fisiológica, as sementes ficam expostas no campo por mais tempo, podendo sofrer perdas pelo ataque de fungos, insetos e variações ambientais, levando a um produto de menor qualidade e produtividade.

Uma maneira de reduzir esses problemas, que pode ainda levar a uma antecipação da colheita, é a dessecação em pré-colheita, prática comum em culturas como sorgo, trigo, soja e algodão. Um dos produtos utilizados nessa modalidade, em feijão, é o amônio-glufosinato, um herbicida de ação total, do grupo químico dos aminoácidos, que é absorvido apenas por via foliar (Lorenzi, 1994; Rodrigues \& Almeida, 1998; Andrei, 1999). Outro produto que apresenta amplo espectro de controle para plantas daninhas é o diquat, utilizado na dessecação em pré-semeadura e que pode, após o registro para a modalidade, constituir em uma opção eficiente na dessecação em pré-colheita

Neste sentido, o presente trabalho teve como objetivo avaliar a viabilidade do herbicida diquat na dessecação em pré-colheita da cultura do feijão, no controle das plantas daninhas e na qualidade dos grãos ou sementes, quando aplicado após a maturação fisiológica.

\section{MATERIAL E MÉTODOS}

O experimento foi instalado na Fazenda Escola "Capão da Onça”, da Universidade Estadual de Ponta Grossa (UEPG), no município de Ponta Grossa, PR, em um Latossolo Vermelho-Escuro de textura argilosa, no ano agrícola 1999/00. A análise do solo apresentou os seguintes valores: $\mathrm{pH}$ $\left(\mathrm{CaCl}_{2}\right)=5,3, \mathrm{Ca}^{++}=3,6 \mathrm{cmol}_{\mathrm{c}} / \mathrm{dm}^{3}, \mathrm{Ca}+\mathrm{Mg}=5,3 \mathrm{cmol}_{\mathrm{c}} / \mathrm{dm}^{3}$, $\mathrm{K}=0,16 \mathrm{cmol}_{\mathrm{c}} / \mathrm{dm}^{3}, \mathrm{P}=9,0 \mathrm{mg} / \mathrm{dm}^{3}, \mathrm{C}=32 \mathrm{~g} / \mathrm{dm}^{3}, \mathrm{H}+\mathrm{Al}=5,7$ $\mathrm{cmol}_{\mathrm{c}} / \mathrm{dm}^{3}$ e $\mathrm{Al}^{+++}=0$. A análise granulométrica revelou (em $\mathrm{g} / \mathrm{kg}$ ): areia -338 , silte -182 , argila -480 .

O sistema de semeadura utilizado foi o plantio direto na palha, com semeadura realizada no dia 25/09/1999, mecanicamente, em linhas espaçadas de $0,45 \mathrm{~m}$, semeando-se em média 16 sementes por metro a uma profundidade de 0,05 m. A cultivar utilizada foi FT Nobre, do tipo agronômico II e de película preta. A emergência das plantas ocorreu no dia 05/10/99. A adubação consistiu da aplicação de $360 \mathrm{~kg} / \mathrm{ha}$ de adubo de fórmula comercial 05-25-25, na semeadura, e 67,5 $\mathrm{kg} / \mathrm{ha}$ de nitrogênio (150 kg/ha de uréia) aos 23 dias após a emergência.

O manejo das plantas daninhas consistiu da dessecação em pré-semeadura com paraquat + diuron $(2,0$ 1/ha de Gramocil) no dia da semeadura e da aplicação de bentazon (1,0 1/ha de Basagran) e sethoxydim (1,0 l/ha de Poast) aos 15 dias após a emergência. O controle de doenças foi realizado com três aplicações preventivas de azoxystrobin (120 g/ ha de Amistar).

O delineamento experimental utilizado foi de blocos ao acaso, com seis tratamentos e quatro repetições. As parcelas apresentaram área total de $16,2 \mathrm{~m}^{2}(6,0 \mathrm{~m}$ x 2,7 m) e área útil de $9,0 \mathrm{~m}^{2}$ (5,0 m x 1,8 m). Os tratamentos, descritos na Tabela 1, foram aplicados através de pulverizador costal, à pressão constante de $2,11 \mathrm{kgf} / \mathrm{cm}^{2}$, mantido por $\mathrm{CO}_{2}$ comprimido, com pontas de jato plano "leque" XR 110-02. Aplicouse o equivalente à $200 \mathrm{~L} /$ ha de calda. A aplicação dos tratamentos foi realizada no dia 06/01/2000, com início às 9 horas. Na pulverização a temperatura do ar era de $29^{\circ} \mathrm{C}$, o tempo estava nublado ( $100 \%$ de nuvens), sem ventos, umidade relativa do ar de $80 \%$ e o solo se encontrava seco. As plantas de feijão apresentavam 67 a $70 \%$ das vagens secas, época que correspondeu a aproximadamente 14 dias antes da colheita. As vagens superiores, mais verdes, já se encontravam em maturação fisiológica, o que permitiu a dessecação.

Tabela 1. Tratamentos utilizados no experimento com feijão. Ponta Grossa, PR, 1999/2000.

\begin{tabular}{lccc}
\hline \multicolumn{1}{c}{$\begin{array}{c}\text { Nome } \\
\text { comum }\end{array}$} & $\begin{array}{c}\text { Dose } \\
\text { (g/ha) }\end{array}$ & $\begin{array}{c}\text { Nome } \\
\text { comercial }\end{array}$ & $\begin{array}{c}\text { Dose } \\
\text { (L/ha) }\end{array}$ \\
\hline Diquat & 200 & Reglone & 1,0 \\
Diquat & 300 & Reglone & 1,5 \\
Diquat & 400 & Reglone & 2,0 \\
Diquat & 500 & Reglone & 2,5 \\
Amônio-glufosinato & 400 & Finale & 2,0 \\
Testemunha & - & - & - \\
& & & \\
\hline
\end{tabular}


As plantas daninhas avaliadas no experimento foram Bidens pilosa (picão-preto), Eleusine indica (capim pé-degalinha) e Digitaria horizontalis (milhã), com 23, 20 e 34 plantas $/ \mathrm{m}^{2}$ respectivamente, que no dia da aplicação dos tratamentos se encontravam na fase de início do florescimento.

As avaliações do efeito dos dessecantes sobre o feijão e as plantas daninhas foram efetuadas aos 4, 7 e 14 dias após a aplicação (DAA) dos tratamentos. A metodologia de avaliação utilizada foi a visual, a mais adequada quando o número de plantas daninhas é elevado (Sociedade Brasileira da Ciência das Plantas Daninhas, 1995). Assim, comparou-se a ação dessecante exercida pelos herbicidas em relação à testemunha, onde " $0 \%$ " correspondeu a "sem ação" e "100\%" a "ação ou necrose total".

O peso de 100 grãos, o vigor, a sanidade de sementes e a percentagem de germinação foram determinados no laboratório de sementes da Cooperativa Batavo. A colheita foi efetuada no dia 20/01/00, manualmente, utilizando-se as plantas da área útil das parcelas. As amostras foram trilhadas e secas até atingirem $13 \%$ de água, quando foram pesadas para determinação da produtividade de grãos.

Os dados obtidos foram submetidos à análise da variância pelo teste $\mathrm{F}$ e as médias comparadas pelo teste de Tukey no nível de $5 \%$ de probabilidade. Nas avaliações de controle foram analisados somente os resultados dos tratamentos com herbicidas, isolando-se a testemunha.

\section{RESULTADOS E DISCUSSÃO}

As temperaturas máximas e mínimas no decorrer do experimento estiveram de acordo com a média da região e a precipitação pluvial foi de $276 \mathrm{~mm}$, bem distribuídas desde a emergência até a aplicação dos tratamentos, condições adequadas ao desenvolvimento da cultura (Silveira \& Stone, 1998), especialmente por não terem ocorridos déficits hídricos no período de florescimento .
Além da dessecação sobre a cultura, os herbicidas dessecantes devem eliminar as plantas daninhas presentes na época da colheita, para facilitar esta operação e diminuir o banco de sementes no local. O diquat, nas doses de 400 e $500 \mathrm{~g} / \mathrm{ha}$, mostrou-se eficiente no controle de Bidens pilosa (Tabela 2). Para Eleusine indica e Digitaria horizontalis foi eficiente nas doses igual ou superiores a $300 \mathrm{~g} / \mathrm{ha}$. O amônioglufosinato controlou eficientemente as três plantas daninhas.

$\mathrm{Na}$ época da aplicação dos tratamentos as plantas de feijão apresentavam 67 a $70 \%$ das vagens secas (Tabela 3). O diquat nas doses igual ou superiores a $300 \mathrm{~g} / \mathrm{ha}$ promoveu controle (desfolha) eficiente e similar ao amônio-glufosinato em todas as avaliações. Para a dose de $200 \mathrm{~g} /$ ha a desfolha foi mais lenta, mas aos 14 dias após a aplicação (DAA) dos tratamentos foi similar aos demais tratamentos.

De um modo geral, o controle (desfolha) para o feijão e para as plantas daninhas foi eficiente para o diquat nas doses igual ou superiores a $300 \mathrm{~g} / \mathrm{ha}$, que se mostrou um tratamento adequado para esta modalidade. Nestas doses o controle foi similar ao amônio-glufosinato, um produto que vem sendo regularmente utilizado. Tanto para o feijão como para as plantas daninhas, os tratamentos se mostraram eficientes na desfolha a partir de $4 \mathrm{DAA}$, indicando a possibilidade da antecipação da colheita, uma vez que o número de folhas verdes era baixo nesta data. Como o feijão apresenta variações bruscas de preço, a colheita precoce pode implicar em um aumento substancial no lucro do agricultor, que pode aproveitar melhor a situação de mercado, pela definição da época da colheita.

A germinação e o vigor das sementes não foram afetados pelos tratamentos com herbicidas aplicados na pré-colheita, uma vez que os resultados foram similares ao observados para a testemunha (Tabela 4). Quanto a umidade dos grãos, aos 6 DAA esta não diferiu entre os tratamentos e a testemunha. No dia da colheita (14 DAA), o tratamento com diquat (500 g/ha) apresentou menor umidade do que a verificada para a testemunha, evidenciando que este trata-

Tabela 2. Controle/desfolha (\%) para Bidens pilosa, Eleusine indica e Digitaria horizontalis, aos 4,7 e 14 dias após a aplicação dos tratamentos (DAA) na cultura do feijão. Ponta Grossa, PR, 1999/2000.

\begin{tabular}{|c|c|c|c|c|c|c|c|c|c|c|}
\hline \multirow{2}{*}{ Tratamento } & \multirow[b]{2}{*}{$\begin{array}{c}\text { Dose } \\
\text { (g/ha) }\end{array}$} & \multicolumn{3}{|c|}{ Bidens pülosa } & \multicolumn{3}{|c|}{ Eleusine inatica } & \multicolumn{3}{|c|}{ Digitaria horizontalis } \\
\hline & & $\begin{array}{c}4 \\
\text { DAA }\end{array}$ & $\begin{array}{c}7 \\
\text { DAA }\end{array}$ & $\begin{array}{c}14 \\
\text { DAA }\end{array}$ & $\begin{array}{c}4 \\
\text { DAA }\end{array}$ & $\begin{array}{c}7 \\
\text { DAA }\end{array}$ & $\begin{array}{c}14 \\
\text { DAA }\end{array}$ & $\begin{array}{c}4 \\
\text { DAA }\end{array}$ & $\begin{array}{c}7 \\
\text { DAA }\end{array}$ & $\begin{array}{c}14 \\
\mathrm{DAA}\end{array}$ \\
\hline Diquat & 200 & $48 \mathrm{~b}$ & $65 c$ & $53 \mathrm{~b}$ & $32 \mathrm{c}$ & $81 \mathrm{~b}$ & $80 \mathrm{~b}$ & $27 c$ & $82 \mathrm{~b}$ & $86 b$ \\
\hline Diquat & 300 & $80 \mathrm{a}$ & $77 \mathrm{~b}$ & $84 \mathrm{a}$ & $75 \mathrm{~b}$ & $100 \mathrm{a}$ & $100 \mathrm{a}$ & $80 \mathrm{~b}$ & $100 \mathrm{a}$ & $100 \mathrm{a}$ \\
\hline Diquat & 400 & $88 \mathrm{a}$ & 91 a & 97 a & $86 \mathrm{ab}$ & $100 \mathrm{a}$ & $100 \mathrm{a}$ & 93 a & $100 \mathrm{a}$ & $100 \mathrm{a}$ \\
\hline Diquat & 500 & $89 a$ & $96 a$ & 98 a & 92 a & $100 \mathrm{a}$ & $100 \mathrm{a}$ & 94 a & $100 \mathrm{a}$ & $100 \mathrm{a}$ \\
\hline Amônio glufosinato & 400 & $93 \mathrm{a}$ & $97 \mathrm{a}$ & $97 a$ & 91 a & $100 \mathrm{a}$ & $99 \mathrm{a}$ & $92 \mathrm{ab}$ & $100 \mathrm{a}$ & $100 \mathrm{a}$ \\
\hline Testemunha & - & 0 & 0 & 0 & 0 & 0 & 0 & 0 & 0 & 0 \\
\hline $\mathrm{F}$ tratamentos & - & 12,6 & 27,2 & 31,1 & 70,1 & 225,0 & 67,9 & 98,0 & 49,0 & 13,4 \\
\hline C.V. $(\%)$ & - & 12,9 & 6,2 & 8,1 & 7,8 & 1,1 & 2,2 & 7,4 & 2,3 & 3,4 \\
\hline
\end{tabular}

Médias seguidas da mesma letra nas colunas não diferem pelo teste de Tukey $(\mathrm{p}<5 \%)$. 
Jeferson Zagonel et al.

Tabela 3. Número de vagens secas na aplicação e avaliação visual de desfolha (\%) do feijão aos 4, 7 e 14 dias após a aplicação dos tratamentos (DAA) na pré-colheita. Ponta Grossa, PR, 1999/2000.

\begin{tabular}{|c|c|c|c|c|c|}
\hline Tratamento & $\begin{array}{c}\text { Dose } \\
(\mathrm{g} / \mathrm{h} \mathrm{a})\end{array}$ & O DAA & $4 \mathrm{DAA}$ & 7 DAA & 14 DAA \\
\hline Diquat & 200 & 70 & $87,5 \mathrm{~b}$ & $85,0 \mathrm{~b}$ & 95,7 a \\
\hline Diquat & 300 & 70 & $93,7 \mathrm{ab}$ & 98,7 a & 99,5 a \\
\hline Diquat & 400 & 69 & $98,5 \mathrm{a}$ & 100,0 a & $100,0 \mathrm{a}$ \\
\hline Diquat & 500 & 67 & $96,5 \mathrm{a}$ & $100,0 \mathrm{a}$ & $100,0 \mathrm{a}$ \\
\hline A mônio-glufosinato & 400 & 70 & $99,0 \mathrm{a}$ & $100,0 \mathrm{a}$ & $100,0 \mathrm{a}$ \\
\hline Testemunha & - & 70 & $76,2 \mathrm{c}$ & $86,2 \mathrm{~b}$ & 96,2 a \\
\hline F tratamentos & - & - & 22,0 & 17,7 & 3,3 \\
\hline C.V. $(\%)$ & - & - & 4,0 & 3,6 & 2,2 \\
\hline
\end{tabular}

Médias seguidas da mesma letra nas colunas não diferem pelo teste de Tukey $(\mathrm{p}<5 \%)$.

Tabela 4. Germinação, vigor e umidade nos grãos de feijão em função de herbicidas aplicados na pré-colheita. Ponta Grossa, PR, 1999/2000.

\begin{tabular}{|c|c|c|c|c|c|}
\hline \multirow[b]{2}{*}{ Tratamento } & \multirow[b]{2}{*}{$\begin{array}{c}\text { Dose } \\
\text { (g/ha) }\end{array}$} & \multirow[b]{2}{*}{$\begin{array}{c}\text { Germinação } \\
(\%)\end{array}$} & \multirow[b]{2}{*}{$\begin{array}{c}\text { Vigor }(72 \mathrm{hs}) \\
(\%)\end{array}$} & \multicolumn{2}{|c|}{ Umidade nos grãos (\%) } \\
\hline & & & & 6 DAA & 14 DAA \\
\hline Diquat & 200 & $95,2 \mathrm{a}$ & 90,5 a & $25,0 \mathrm{a}$ & $18,2 \mathrm{ab}$ \\
\hline Diquat & 300 & $92,5 \mathrm{a}$ & $89,7 \mathrm{a}$ & 26,7 a & $17,8 \mathrm{ab}$ \\
\hline Diquat & 400 & 93,2 a & 89,5 a & $20,5 \mathrm{a}$ & $16,9 \mathrm{ab}$ \\
\hline Diquat & 500 & 95,5 a & $89,5 \mathrm{a}$ & $20,3 \mathrm{a}$ & $16,7 \mathrm{a}$ \\
\hline Amônio-glufosinato & 400 & $91,7 \mathrm{a}$ & 89,2 a & 24,2 a & $17,3 \mathrm{ab}$ \\
\hline Testemunha & - & $93,5 \mathrm{a}$ & 90,2 a & $24,4 \mathrm{a}$ & $18,7 \quad b$ \\
\hline $\mathrm{F}$ tratamentos & - & 2,0 & 0,12 & 2,73 & 3,41 \\
\hline C.V. $(\%)$ & - & 2,2 & 3,0 & 13,1 & 4,8 \\
\hline
\end{tabular}

Médias seguidas da mesma letra nas colunas não diferem pelo teste de Tukey ( $<<5 \%$; DAA = dias após a aplicação dos tratamentos.

mento, por promover a desfolha mais rápida nas plantas de feijão, também proporciona uma perda mais rápida da água nos grãos, beneficiando a colheita e a secagem posterior.

Estes resultados mostram que os tratamentos não afetaram a germinação e o vigor dos grãos, indicando que os mesmos podem ser utilizados como semente, com a mesma qualidade daqueles que não foram submetidos à dessecação. França Neto et al. (1999), trabalhando com soja, observaram que o diquat não afetou a sanidade e a germinação das sementes, o que confirma os resultados do presente trabalho.

O peso de 100 grãos e a produtividade não foram afetados pelos tratamentos com dessecantes, uma vez que os re-

Tabela 5. Peso de 100 grãos e produtividade do feijão em função de herbicidas aplicados na pré-colheita. Ponta Grossa, PR, 1999/2000.

\begin{tabular}{lccc}
\hline \multicolumn{1}{c}{ Tratamento } & $\begin{array}{c}\text { Dose } \\
(\mathbf{g} / \mathbf{h a})\end{array}$ & $\begin{array}{c}\text { Peso de 100 } \\
\text { grãos (g) }\end{array}$ & $\begin{array}{c}\text { Produtividade } \\
(\mathbf{k g} / \mathbf{h a})\end{array}$ \\
\hline Diquat & 200 & $20,2 \mathrm{a}$ & $2172 \mathrm{a}$ \\
Diquat & 300 & $20,8 \mathrm{a}$ & $2040 \mathrm{a}$ \\
Diquat & 400 & $20,5 \mathrm{a}$ & $1959 \mathrm{a}$ \\
Diquat & 500 & $21,1 \mathrm{a}$ & $1878 \mathrm{a}$ \\
Amônio-glufosinato & 400 & $20,6 \mathrm{a}$ & $2263 \mathrm{a}$ \\
Testem & - & $20,9 \mathrm{a}$ & $2136 \mathrm{a}$ \\
& & 0,41 & 1,66 \\
F tratamentos & - & 4,6 & 10,6 \\
C.V.(\%) & - &
\end{tabular}

Médias seguidas da mesma letra nas colunas não diferem pelo teste de Tukey $(\mathrm{p}<5 \%$ ). 
sultados foram similares aos observados na testemunha sem tratamento (Tabela 5).

Os resultados obtidos mostram que o diquat nas doses igual ou superiores a $300 \mathrm{~g} / \mathrm{ha}$, além de não afetar características importantes como qualidade e peso de grãos, também não afeta a produtividade. Além disso, proporciona uma maior uniformidade das plantas na ocasião da colheita, que foi realizada com as plantas daninhas quase totalmente secas, facilitando a operação.

\section{CONCLUSÕES}

O diquat nas doses de 300,400 e $500 \mathrm{~g} /$ ha foi eficaz no controle/desfolha de Bidens pilosa, Eleusine indica e Digitaria horizontalis.

$\mathrm{Na}$ desfolha do feijão, o diquat foi eficiente em todas as doses, a partir de quatro dias após sua aplicação, possibilitando a antecipação da colheita.

Os dessecantes utilizados não afetaram a germinação, o vigor e o peso dos grãos, e mostraram produtividade similar à verificada na testemunha, sendo o tratamento com diquat (500 g/ha) o que proporcionou grãos com menor umidade em relação à testemunha na época da colheita.

\section{LITERATURA CITADA}

ALMEIDA, F.S.; RODRIGUES, B.N.; OLIVEIRA, V.S. Controle de plantas daninhas na cultura do feijão no Estado do Paraná. Londrina, PR: IAPAR, 1989. 22p. (Circular, 32).

ANDREI, E. Compêndio de Defensivos Agrícolas. São Paulo: Organização Andrei Editora, 1999. 672p.

FRANÇA NETO, J.B.; GAZZIERO, D.L.P.; KRZYZANOWSKI, F.C.; HENNING, A.A.; COSTA, N.P. Efeitos da aplicação de dessecantes foliares sobre a qualidade da semente de soja - safra 1997/98. In: REUNIÃO DE PESQUISA DE SOJA DA REGIÃO CENTRAL DO BRASIL, 21. Dourados, MS, 1999. Resumos... Londrina: Embrapa Soja, p.223. (Documentos, 7).
GELMINI, G.A.; ROSTON, A.J. Herbicidas para a cultura do feijão. Campinas: CATI, 1980. 36p. (Boletim Técnico, 147)

LORENZI, H. Manual de identificação e controle de plantas daninhas. 4 ed. Nova Odessa, SP: Editora Plantarum, 1994.

PITELLI, R.A.; DURIGAN, J.C. Terminologia para períodos de controle e de convivência das plantas daninhas em culturas anuais e bianuais. In: CONGRESSO BRASILEIRO DE HERBICIDAS E PLANTAS DANINHAS, 15. Belo Horizonte, 1984. Resumos... Belo Horizonte: SBHED, 1984. p.37.

PORTELA, C.M.O.; COBUCCI, T. Praticabilidade agronômica da dessecação em pré-colheita do feijoeiro. In: REUNIÃO NACIONAL DE PESQUISA DE FEIJÃO, 6. Goiás, GO, 1999. Anais... Salvador: EBDA/Embrapa, 1999. p.507-510.

RODRIGUES, B.N.; ALMEIDA, F.L.S.; SIQUEIRA, R.; FIGUEIREDO, P.R.A. Plantas daninhas e seu controle. In: FUNDAÇÃO INSTITUTO AGRONÔMICO DO PARANÁ. O feijão no Paraná. Londrina, PR: IAPAR, 1989. p.167-188 (Circular, 63).

RODRIGUES, B.N.; ALMEIDA, F.S.L. Guia de Herbicidas. 4 ed. Londrina, PR: Ed. dos Autores, 1998. 648p.

SILVEIRA, P.M.; STONE, L.F. Irrigação. In: VIEIRA, C., PAULA JUNIOR, T.J., BORÉM, AA. ed. Feijão: aspectos gerais e cultura no Estado de Minas Gerais. Viçosa: UFV, 1998. p.181-221.

SOCIEDADE BRASILEIRA DA CIÊNCIA DAS PLANTAS DANINHAS. Procedimentos para instalação, avaliação e análise de experimentos com herbicidas. Londrina: SBCPD, 1995. $42 \mathrm{p}$.

ZAGONEL, J.; PRESTES, J.R.G.; PIANA, R.O.; NASCIMENTO, R.A.A. Influencia da época de controle das plantas daninhas sobre a produtividade do feijão. In: REUNIÃO NACIONAL DE PESQUISA DE FEIJÃO, 6. Goiás, GO, 1999. Anais... Salvador: EBDA/Embrapa, 1999. p.491-494. 
